\title{
Mechanical behavior of composite materials using the finite element analysis
}

\author{
Emilia Sabau ${ }^{1, *}$, Adrian Popescu ${ }^{1}$ and Cristian Vilau ${ }^{1}$ \\ ${ }^{1}$ Technical University of Cluj-Napoca, Manufacturing Engineering Department, 103-105 Muncii Bvd. \\ Cluj-Napoca, Romania
}

\begin{abstract}
A finite element analysis software has been used in order to determine several mechanical properties for samples made from unidirectional composite materials. Plates from reinforced unidirectional fiber glass polymer composites obtained by compression hand lay-up process were studied.Tensile tests were performed upon samples with different number and orientation of the composite ply layup.
\end{abstract}

\section{Introduction}

Composite materials represent a class of engineering materials with great scientific and technical interest. They are not only a perfect replacement for ferrous or non-ferrous materials, but also materials to solving technical problems in the whole range of different industries. Currently its properties and quality, polymer composite materials have a wide applicability in a number of areas such as building and civil engineering, electrical engineering, electronics, road, rail and marine, aeronautical and aerospace technique etc. [1-3].

The major advantage of the composites consists in the possibility of modeling the properties and obtaining a wide range of materials. In most cases, the composite comprises a base material, the matrix, in which a complementary material is dispersed in the form of fibers or particles, and the main properties that are intended to be obtained in an improved form are: tensile strength, wear resistance, density, high temperature resistance, superficial hardness, dimensional stability, vibration damping capacity.

Engineering calculation is an essential part of the design process, be it constructive or technological design. The great variety of issues that the engineer has to solve is reflected in the many computational methods currently used. These methods have gradually developed, as the theoretical and technological knowledge accumulates, in the last half century [4-7].

The finite element method is currently the most widely used numerical solution for engineering problems. The Finite Element Analyses (FEA) is a numerical solution of the problems that can be expressed in mathematical language in the form of partial derivative equation systems [8].

\footnotetext{
${ }^{*}$ Corresponding author: emilia.sabau@tcm.utcluj.ro
} 
When applying FEA, the occupied domain of the physical system that we analyse, is meshed in finite subdomains bounded by rectilinear or curvilinear boundaries. Through this operation, the real system is replaced with a network of so-called finite elements.

The differential equations that describe the system behavior will be verified for each element. The mathematical construction of the finite elements ensures a certain degree of approximation continuity at crossing of the boundary between the elements. Continuity is realised using remarkable points associated with the elements (known as nodes). In fact, the approximation of the exact solution problem results as a function of the unknown values in the respective nodes. Applying FEA, we obtain a system of equations that is numerically solved in relation to nodal unknown values.

The mesh uses thousands or even tens of thousands of finite elements.

In the last years, a series of finite element computational programs have appeared and function as integrated modules in CAD systems. One example is SolidWorks Simulation.

The paper analyse unidirectional composite samples using SolidWorks Simulation Software. The program can optimize material selection, the number and orientation of the composite ply layup to ensure product quality, performance and factor of safety.

Using SolidWorks Simulation Software to analyse the composite parts we can reduce the need for costly prototypes and save time and development costs. Each layer can be defined by a unique set of material properties and orientation, giving the designer maximum control to find the optimum layup and material for maximum product performance [9-15].

The paper will analyze the mechanical characteristics for different polymer composite structures, both by finite element simulations and by experimental determinations. It will identify all factors influencing the quality, productivity and competitiveness of products made and will study all the phenomena that accompany the process of forming parts.

The results will be used to obtain new reinforced polymer composites at lower costs, technical and mechanical properties as high in order to use them in more and more fields.

\section{Method and materials}

The material used is unidirectional fibers glass tissue $225 \mathrm{~g} / \mathrm{m}^{2}$ and polyester resin, Poliester Norpol 440-M750 type, as a matrix.

The polyester resin is orthophthalic thixotropized. The technical properties of the resin are: Brookfield viscosity at $25^{\circ} \mathrm{C}$ : $250-350 \mathrm{mPa}$.s; Density at $25^{\circ} \mathrm{C}: 1350 \mathrm{~kg} / \mathrm{m}^{3}$; Gel time with 2\% MEC (methyl-ethyl-ketone) in 100g resin: 8-15 min; Exothermic peak: 160-190 ${ }^{\circ} \mathrm{C}$; Exothermic peak time: 15-23 min; Colour: transparent pink.

The manufacturing process was achieved at ambient temperature of $20{ }^{\circ} \mathrm{C}$. The technology applied was compression hand lay-up technology, [16-19]. Different plates with different reinforced grade were obtained. Separate composite plates from each of reinforced type were made. The samples were cut from the obtained plates on three angles directions of the fibers, like $0^{\circ}, 90^{\circ}$ and $45^{\circ}$ relative to direction of stress.

To determine the mechanical resistances of composite plates was done experimental trials at tensile tests.

The samples dimensions obtained from unidirectional tissue and tested on longitudinal direction were cut at $15 \times 1 \times 250 \mathrm{~mm}$ dimensions according to ISO 527-5 A, and the samples dimensions obtained from unidirectional tissue and tested on transversal direction were cut at $25 \times 2 \times 250 \mathrm{~mm}$ dimensions, according to ISO $527-5 \mathrm{~B}$.

In order to highlight the influence of pressure on the mechanical properties at tensile tests of the lamine groups, unidirectional composite plates were made by compression hand lay-up process using a pressure of $0,16 \mathrm{MPa}$. Before polymerization, after the layers were achieved, the mold that consists of two metal plates $(300 \times 300 \mathrm{~mm})$, is compressed with a 
power-press to homogenize the structure, to remove the exceeded resin and to increase the reinforcement degree. The compression of composite plates was achieved on the tensilecompression test machine, which is provided with calibrated dial indicating the value of applied force.

Tensile tests were performed upon samples with fibers tilted at $0^{\circ}, 45^{\circ}$ and $90^{\circ}$ angles relative to direction of stress.

The results of the tensile tests for the samples that use unidirectional fabric are shown in Table 1, where: $M_{f}$ - reinforced grade, $A=b x h$ - section aria of the sample, $E$ - elastic modulus, $F_{\max }-$ maximum broken force, $\sigma_{\mathrm{r}}-$ tensile strength.

Table 1. UD $225 \mathrm{~g} / \mathrm{m}^{2} /$ Polyester Norpol 440-M750 composite

\begin{tabular}{|c|c|c|c|c|c|c|}
\hline $\begin{array}{l}\text { Nr. } \\
\text { crt. }\end{array}$ & $\begin{array}{c}M_{f} \\
{[\%]}\end{array}$ & Angle & $\begin{array}{c}A=b x h \\
{\left[\mathrm{~mm}^{2}\right]}\end{array}$ & $\begin{array}{c}E \\
{[\mathrm{MPa}]}\end{array}$ & $\begin{array}{l}F_{\max } \\
{[\mathrm{N}]}\end{array}$ & $\begin{array}{c}\sigma_{r} \\
{[\mathrm{MPa}]}\end{array}$ \\
\hline 1. & \multirow{3}{*}{65} & $0^{\circ}$ & $15 \times 1=15$ & 10895 & 7023 & 468,2 \\
\hline 2. & & $45^{\circ}$ & \multirow{2}{*}{$25 \times 2=50$} & 3864 & 2810 & 56,2 \\
\hline 3. & & $90^{\circ}$ & & 2650 & 1940 & 38,8 \\
\hline
\end{tabular}

It is noted that in the case of the UD $225 \mathrm{~g} / \mathrm{m}^{2}$ / Polyester Norpol 440-M750 composite, the value of the breaking strength at $45^{\circ}$ fiber reinforcement angle decreases with $87,99 \%$ compared to the reinforcement at $0^{\circ}$ and with $91,71 \%$ in the case of reinforcement at $90^{\circ}$.

\section{Finite element analyses}

The Finite Element Analyses is a numerical solution of the problems that can be expressed in mathematical language in the form of partial derivative equation systems. At the FEA base exists the meshing concept. In very intuitive terms, the meshing operation is a division of the spatial domain occupied by the analyzed body into regions of limited sizes known as finite elements.

This paper analyses samples using the SolidWorks Simulation Software. The analysis proposes as the first objective to determine the stress state and the deformation of the samples. A mesh with 3731 nods and 1732 elements has been generated, Figure 1.

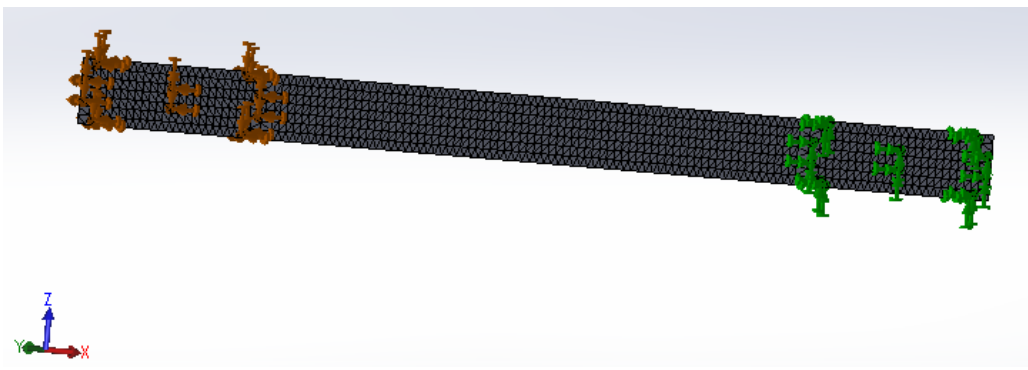

Fig. 1. Finite element network and restrictions.

The right side of the sample is rigid fixed at the end, and at the left side we have a imposed displacement of $4,50 \mathrm{~mm}$, presented in Figure 2. The samples realized from unidirectional tissue with polyester matrix was made from 3 plies with the thickness of 0,33 $\mathrm{mm}$ at a reinforced angle by $0^{\circ}$. 


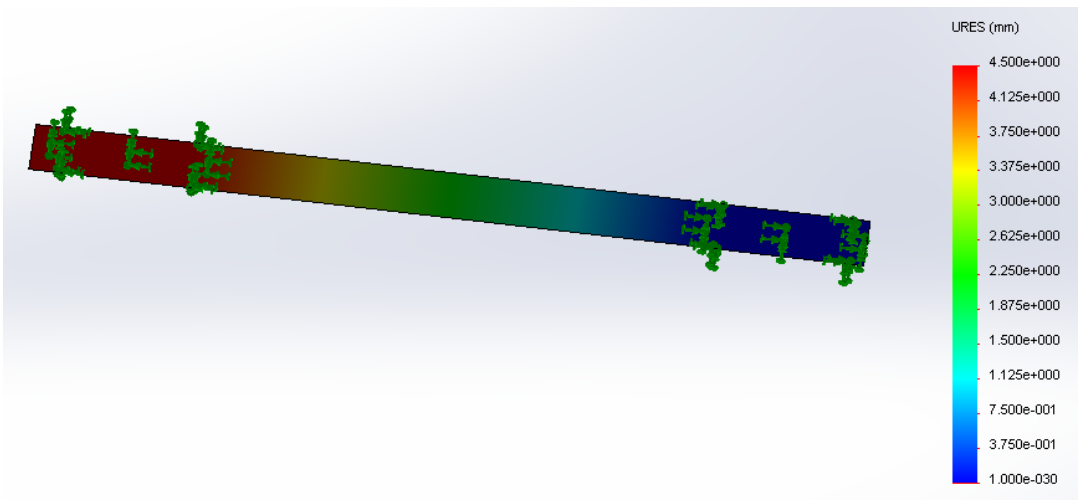

Fig. 2. Displacement distribution.

The SolidWorks Simulation finite elements program is used to point out the applicability of failure samples. The deformation of samples at tensile testing was analyzed. The visualization and interpretation of the simulation's results have been made with the help of SolidWorks Simulation module. This realizes the graphical representation of the numerical results. Thus, Figure 3 presents the distribution of von Mises equivalent stress in configuration of failure sample. It is observed that the maximum value for unidirectional tissue is $436,383 \mathrm{~N} / \mathrm{mm}^{2}$.

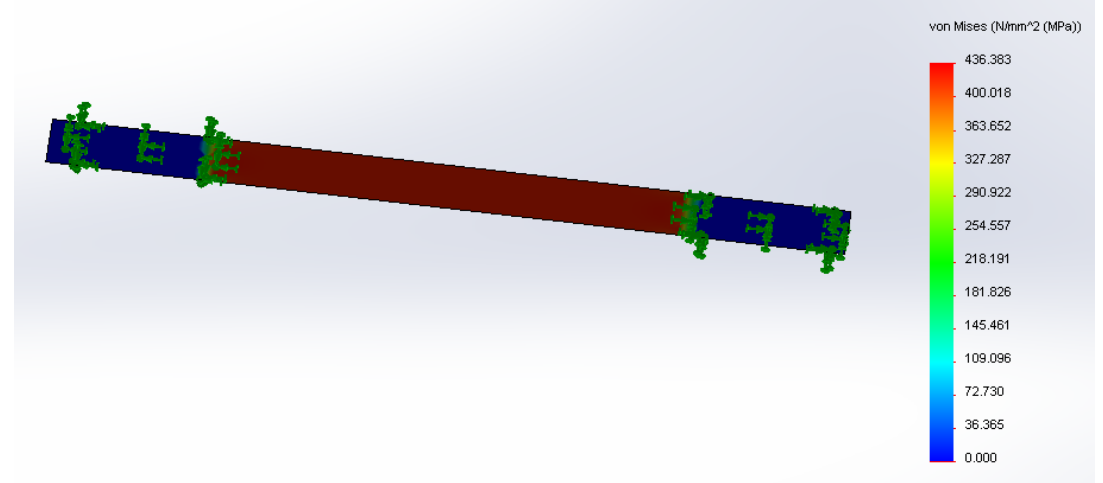

Fig. 3. Distribution of von Mises equivalent stress, reinforced angle by $0^{\circ}$.

We can conclude that the composite that use in the structure unidirectional tissue obtained similar values for the result forces, both in the experimental part and in the FEA simulation (Table 1, Figure 4).

\begin{tabular}{|c|c|c|}
\hline \multicolumn{3}{|c|}{ Reaction Force $(\mathrm{N})$} \\
\hline Component & Selection & Entire Model \\
\hline Sum X: & 0. & -0.055176 \\
\hline Sum Y: & 0 . & 7. $189 \mathrm{E}-012$ \\
\hline Sum Z: & 0 . & -0.40556 \\
\hline Resultant: & 0. & 0.4093 \\
\hline
\end{tabular}

\begin{tabular}{|l|r|r|}
\hline \multicolumn{3}{|l|}{ Reaction Moment (N-m) } \\
\hline Component & Selection & Entire Model \\
\hline Sum X: & 0. & $7.4725 E-013$ \\
Sum Y: & 0. & 0. \\
Sum Z: & 0. & $9.2271 E-013$ \\
\cline { 1 - 1 } Resultant: & 0. & $1.1873 E-012$ \\
\hline
\end{tabular}

Fig. 4. Result force for UD $225 \mathrm{~g} / \mathrm{m}^{2} /$ Polyester Norpol 440-M750 composite.

Also, two other particular cases were analyzed, when the sample was realized from 6 plies with the thickness of $0,33 \mathrm{~mm}$ at a reinforced angle by $45^{\circ}$ and $90^{\circ}$. In these cases, the distribution of von Mises equivalent stress in configuration of failure sample is shown in 
Figure 5, respectively Figure 6 . It is observed that, the maximum value for unidirectional tissue with a reinforced angle of $45^{\circ}$ is $86,735 \mathrm{~N} / \mathrm{mm}^{2}$.

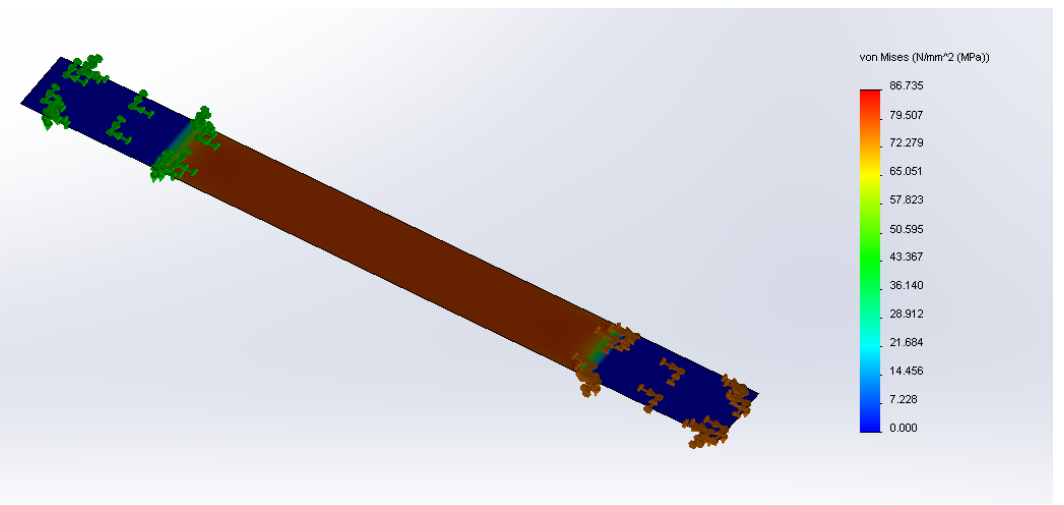

Fig. 5. Distribution of von Mises equivalent stress, reinforced angle by $45^{\circ}$.

The maximum value for unidirectional tissue with a reinforced angle of $90^{\circ}$ is 54,548 $\mathrm{N} / \mathrm{mm}^{2}$.

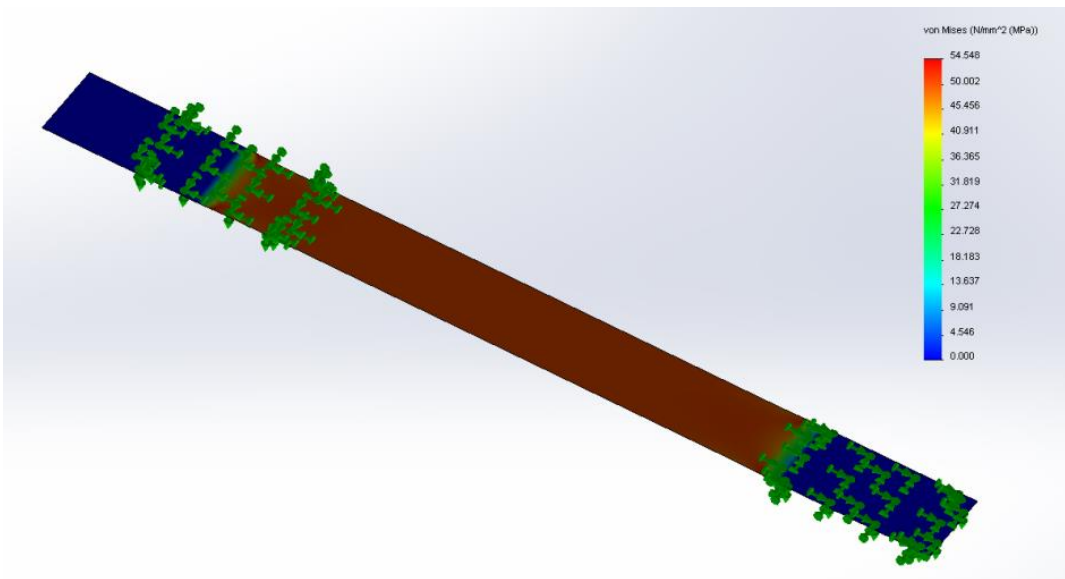

Fig. 6. Distribution of von Mises equivalent stress, reinforced angle by $90^{\circ}$.

The presented examples demonstrate the possibility of implementing the proposed model in the structure of finite element analysis programs. We can observe, that the FEA results are very close to the test results.

\section{Conclusions}

The paper analyzes the mechanical characteristics for unidirectional glass polyester composite structures, both by finite element simulations and by experimental determinations.

The mechanical behavior of the polymer-composite materials depends by the nature and by the reinforcing material, and by the technological procedure. The manufacturing technology for the unidirectional composite plates was compression hand lay-up processes. The experiments consist in tensile tests, fibers being tilted at $0 \stackrel{\circ}{\circ}, 45^{\circ}$ and $90^{\circ}$ angles, relative to direction of stress. Several variants of composite samples were 
designed, by taking into account the reinforcement degree, the number and the orientation of the plies, the thickness ply, Young modulus, maximum broken force, tensile strength. The structure of the reinforcing material will influence the mechanical characteristics.

Applying a pressure to the composite plate during the hand lay-up process is beneficial because by the removal of exceeded resin the reinforcement degree increases which leads to a growth of mechanical strength characteristics.

By using SolidWorks Simulation Software to analyse the composite parts we reduce the need for costly prototypes and save time and development costs. Each layer can be defined by a unique set of material properties and orientation, giving the designer maximum control to find the optimum layup and material for maximum product performance.

We conclude, that the composite, that use in the structure unidirectional tissue, obtained similar values for the result forces, both in the experimental part and in the FEA simulation.

Making a comparison between results, it is obvious that the FEA results are very close to the test results. This means that the FEA is validated by the test results.

This work was supported by a grant of the Romanian National Authority for Scientific Research and Innovation, CNCS/CCCDI-UEFISCDI, project number PN-III-P2-2.1-BG-2016-0216, within PNCDI III and the H2020 AMaTUC project (GA 691787).

\section{References}

1. E.J. Barbero, Introduction to Composite Materials Design (West Virginia University, USA, 1998)

2. D. Gay, Matériaux Composites (Hermes, Paris, 1997)

3. M. Berthelot, Matériaux Composites. Comportement mécanique et analyse des structures (EDP TEC\&DOC, Paris, 1999)

4. R.M. Jones, Mechanics of Composite Materials (Taylor and Francis, Philadelphia, 1999)

5. L.P. Kollar, G.S. Springer, Mechanics of Composite Structures (Cambridge University Press, Cambridge, 2003)

6. V.V. Vasiliev, E.V. Morozov, Mechanics and Analysis of Composite Materials (Elsevier Science, London, 2001)

7. E.E. Gdoutos, Fracture mechanics. An introduction. Second Edition (Springer, USA, 2005)

8. D.V. Hutton, Fundamentals of finite element analysis (Elizabeth A. Jones Publishers, USA, 2004)

9. E.J. Barbero, D.H. Cortes, Comp. Part B: Eng. 41, 124 (2010)

10. R.H. Lopez, M.A. Luersen, E.S. Cursi, Comp. Part B: Eng. 40, 731 (2009)

11. N.M. Hassan, R.C. Batra, Comp. Part B: Eng. 39, 66 (2008)

12. W.K. Lim, W.K. Jeong, E.K. Tschegg, Comp. Part B: Eng. 41, 94 (2010)

13. K. Bruyere, Revue des composites et des materiaux avonces, 76, 69 (1997)

14. D. Gay, J. Gambelin, Une aproche simple du calcul des structures par la methode des elements finis (Hermes, Paris, 1991)

15. O.O. Ochoa, J.N. Reddy, Finite element analysis of composite laminates (Kluwer Academic Publishers, USA, 1992)

16. P. Bere, M. C. Dudescu, N. Balc, P. Berce, O. Nemes, A. M. Iurian, Mat. Plast. 51, 2 (2014)

17. A. Popescu, L. Hancu, P. Bere, Appl. Mec. Mat. 371, 394 (2013)

18. E. Sabău, N. Bâlc, P. Bere, AJME 9, 4 (2011)

19. P. Bere, P. Berce, O. Nemeş, Comp. Part B: Eng. Int. J. 43, 2237 (2012) 